\title{
Article
}

\section{The Adoption Challenge: An Analysis of Research Methods in JIBS}

\author{
Stewart R. Miller', Catherine Welch ${ }^{2}$, Agnieszka Chidlow ${ }^{3}$, Bo Bernard Nielsen ${ }^{4}$, Diletta Pegoraro ${ }^{3}$, Maria Karafyllia ${ }^{5}$ \\ 1 The University of Texas - San Antonio, USA, ${ }^{2}$ The University of Sydney, Australia, ${ }^{3}$ The University of Birmingham, UK, ${ }^{4}$ Tue University of Sydney, \\ Australia, 5 The University of Nottingham, UK \\ Keywords: ethnography, heckman models, complexity distance, translational distance, research methods, survey, credibility, data equivalence
} https://doi.org/10.46697/001c.23472

\section{AIB Insights}

Vol. 21, Issue 2, 2021

\begin{abstract}
This study introduces the concepts of translational distance and complexity distance to explain challenges to adoption of research methods in JIBS. We examine three analytical techniques and data collection approaches: (1) Heckman models, (2) ethnographic studies, and (3) data collection equivalence procedures in survey-based research. We note that progress has been made to reduce translational and complexity distance for analytical techniques. However, concerns remain for data collection equivalence and ethnography as IB scholars are using increasingly advanced analytical techniques on less credible data.
\end{abstract}

\section{INTRODUCTION}

This $A I B$ Insights article aims primarily at IB scholars, editors, and reviewers as suppliers of IB knowledge, and indirectly at external stakeholders as procurers of cross-national data (e.g., The World Bank, OECD, National Offices of Statistics). Leveraging insights from a recent article examining the evolution of research methodology in the Journal of International Business Studies (JIBS) between 1970-2019 (Nielsen, Welch, et al., 2020), we further enhance understanding of research methods by examining adoption of methodological innovations by IB scholars publishing in JIBS. Our adoption cases show that distance can influence adoption rates with respect to method used to gather and analyze data used to formulate policy decisions.

We discuss two forms of distance: translational distance and complexity distance. Translational distance is defined as the degree of perceived applicability, an innovation developed in one scholarly field has for a different scholarly field. Complexity distance reflects the degree of perceived difficulty associated with a given methodological innovation (e.g., data collection and analytical technique) compared to existing applications within a given scholarly field. The degree of difficulty entails time-based and monetary costs to learn and execute the methodological innovation. Furthermore, we explain how editorial and scholarly initiatives, as well as technical advances, affect translational distance and/or complexity distance over time and, in turn, adoption rates over the 50-year period in JIBS.

We posit that understanding barriers to methodological change - including no changes and delayed changes - can promote a deeper understanding of a field of research, by enriching the ongoing discourse on methodological practices in the (here IB) field (Eden \& Nielsen, 2020). Building on the data collected by Nielsen, Welch, et al. (2020), we develop three discrete cases in order to examine adoption of research methods in the IB field.

\section{METHODS}

The three case studies on the adoption of particular analytical techniques and data collection approaches in IB research are (1) Heckman models, (2) ethnography, and (3) data collection equivalence procedures in survey-based research. We selected these three cases in order to provide breadth across methods (e.g., see Nielsen, Welch, et al., 2020: 1480) - archival quantitative (Heckman), survey quantitative (data equivalence), and qualitative (ethnography). We also selected them because they capture both data collection (data equivalence; ethnography) and analytical techniques (Heckman and ethnography), two of the primary research phases in relation to research methodology (Nielsen, Eden, \& Verbeke, 2020). Lastly, we chose them because we noted the variance in their adoption rates which served our purpose illustratively. For our text and figures, we coded adoption as JIBS papers that actually used ethnography, Heckman models and data equivalence, respectively.

\section{CASE 1 - DELAYED ADOPTION IN IB RESEARCH: HECKMAN MODELS}

Heckman's (1979) path breaking research on self-selection (i.e., individuals/organizations self-select to engage in actions) paved the way for what has become known as the Heckman model. The first stage is a selection equation estimated with a Probit model, which predicts which entities engage in an action. The second stage consists of the individuals/firms that engaged in the action and it is typically 


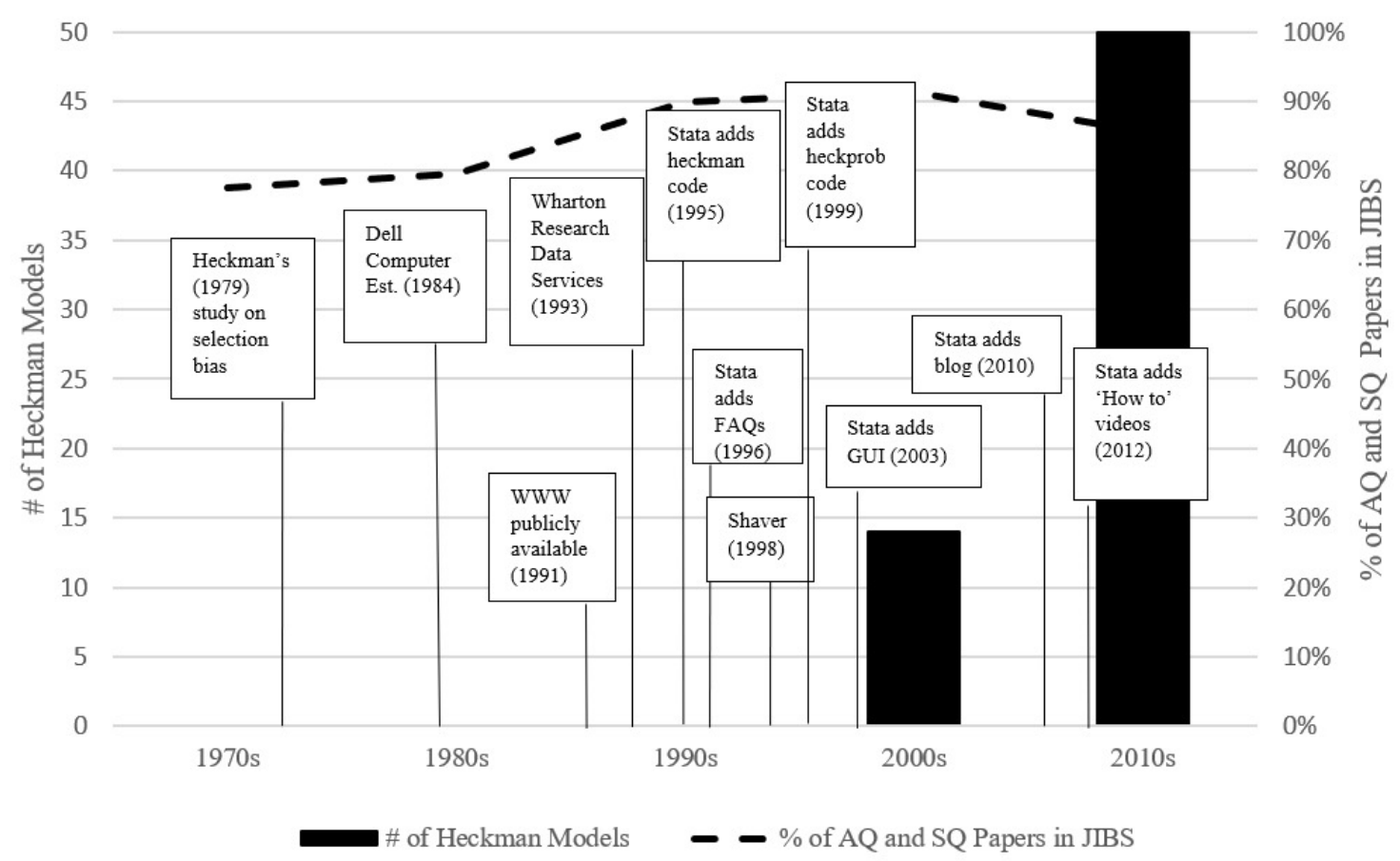

Figure 1: Delayed Adoption in IB Research: Heckman Models 1,2,3

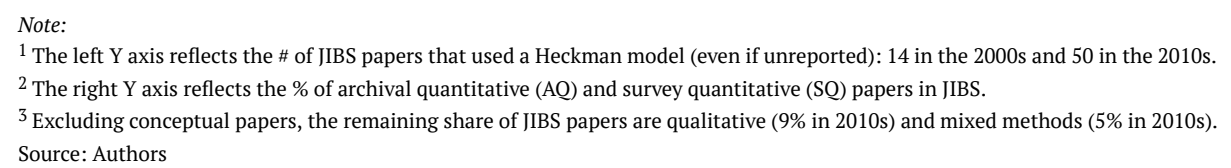

estimated with regression. A key to the Heckman model is capturing selection bias - or Inverse Mills ratio. Computation of the Inverse Mills ratio requires familiarity with advanced statistical coding, which creates significant learning costs.

Heckman's (1979) influential innovation did not make a substantial impact in JIBS until after Shaver (1998) published his paper translating this method into IB by applying it to entry mode choice, thus lowering translational distance. Between 1979 and 1998, there were computational, software and data innovations. Moreover, software providers such as Stata developed coding for Heckman models (1995 and 1999) to facilitate usage (see Figure 1). We contend that complexity distance remained high because in many cases, the researcher still needed to calculate the inverse Mills ratio. Broader adoption of this method occurred in the 2000s (14 Heckman papers) when Stata developed a graphical user interface and developed user-friendly videos, thus lowering learning costs and complexity distance. The cumulative effect of these developments led to the eventual, yet, delayed adoption of this analytical technique as can be seen by the substantial adoption in the 2010 s (50 Heckman papers). ${ }^{1}$

\section{CASE 2 - DELAYED LOW ADOPTION IN IB RESEARCH: ETHNOGRAPHY}

Ethnography is a qualitative research method that focuses on observing social interactions, rituals, and cultural practices of a group of people. This form of qualitative research involves participant observation and immersion in the selected field setting. It originated in anthropology, which introduces high translational distance. Nonetheless, the emerging area of cross-cultural research was influenced by anthropological work, such as Hall (1959). Emic approaches (such as ethnography) that seek to understand culture on its own terms were recognized as important by IB researchers such as Green \& White (1976). But immersion in a particular setting is time intensive and very costly, thus creating very high complexity distance for IB scholars within a multinational setting (see also Eden \& Nielsen, 2020). Immersion can also bring about translational distance as IB scholars wrestle with applicability to firms with operations in many countries (and facing language barriers).

Ethnography exhibited non-adoption by IB researchers in JIBS during the first decades (see Figure 2). The dearth of ethnographic studies prevailed despite JIBS editorial teams in the 1970s identifying anthropology as one of the refer-

1 IB studies that deal with endogeneity have much in common with the Heckman case, however, the delay in adoption is more protracted. For this reason, we selected only the Heckman case. Indeed, endogeneity models date back to Wright's (1928) work on supply and demand of flaxseed as well as Theil's (1953) work that developed a technique referred to as two-stage least squares. 
ence disciplines for IB (e.g., Dymsza \& Vambery, 1977). In 1982, a call for papers for a JIBS special issue on cross-cultural management explicitly encouraged ethnographic approaches, but no ethnography-related content was included in the special issue when it was published in 1983. This is despite the revival in interest in ethnography that was occurring in management at the time (e.g., Van Maanen, 1979). After the special issue call for papers, ethnography was not mentioned again in JIBS until 1999, and then only in passing (Lenartowicz \& Roth, 1999). While concepts and theories were imported from anthropology, anthropological techniques were not, leading to a missed opportunity for IB methodological practices to become more inter-disciplinary (e.g., Cantwell \& Brannen, 2011).

The very first JIBS study based on ethnography was reported as a mixed-method study (Brannen \& Peterson, 2009). Two more traditional ethnographies were published in a special issue on qualitative research. These remain the only such studies published in the journal. Other studies mention ethnographic interviews (e.g., Boussebaa, Sinha, \& Gabriel, 2014: 1157) but omit participant observation; or mention participant observation but do not draw on the results extensively (Shapiro, Ozanne, \& Saatcioglu, 2008). This low adoption of the ethnographic approach was highlighted in Westney and Van Maanen's (2011) critique of the prevalence of 'casual ethnography' and underscores the need for what they call more serious ethnographic research within the discipline.

IB scholars have continued to call for the use of emic approaches, such as ethnography (e.g., Tung \& Stahl, 2018). This recognition is occurring concurrently with ethnographic innovations well suited to international business; notably online ethnography, multi-sited ethnography, and multi-modal ethnography (see Rouleau, De Rond, \& Musca, 2014). Yet editorial initiatives in the past decade, such as the special issue on qualitative research in JIBS in 2011, have not reduced complexity distance due, in part, to steep learning and time-based immersion costs that escalate during the early years of an IB scholar's professional career brought on by publishing pressures. Assuming most IB scholars have not been trained to conduct an ethnographic study, we contend that the learning costs and opportunity costs may be high for mid-career scholars, even ones who conduct other forms of qualitative research such as case studies. First, they have to learn how to conduct properly an ethnographic study - which may involve immersion time as an apprentice. Next, the scholar will need to identify a suitable project and immersion setting. Then, the scholar will need to plan for the immersion. Moreover, mid-career and senior faculty tend to get engaged in developing PHD students and other service commitments that raise the timebased costs of immersion. We note that journal leadership teams may influence the low adoption rate by not effectively conveying the importance of ethnography, which can lower translational distance.

\section{CASE 3 - LOW ADOPTION IN IB RESEARCH: DATA COLLECTION EQUIVALENCE PROCEDURES IN SURVEY- BASED STUDIES}

Survey-based studies have been published in JIBS since the 1970s. However, the amount of information regarding questionnaire administration or translation was often lacking. While insufficient detail was somehow consistent with prior IB studies at that time, it compromised survey data collection equivalence that, in turn, diminished replicability (Nielsen, Welch, et al., 2020).

Dillman (1978) developed the Total Design Method (ToDM) for survey research in the sociology field, which introduced translational distance for IB scholars. Dillman's framework was only cited once during the 1980s. A similar pattern can be found in relation to the language translation and back-translation issues of the questionnaire used, which have been long recognized as critical for cross-language survey research in the psychology field (Brislin, 1970). Thus, translational distance was moderate while complexity distance was very high. Recognition of any translation procedures, as well as the use of non-English languages, was also rare during the 1970s and 1980s (see Figure 3), despite being acknowledged as significant issues in JIBS (Green \& White, 1976; Sekaran, 1983).

As IB researchers expanded their international empirical data collection horizons in the 1990s, they continued to use postal and self-administered surveys as their main data collection modes. Dillman (2000) updated his original ToDM framework to the five-step Tailored Design Method (TaDM) to accommodate technological advances relating to internet and web-based surveys, which are now supported by multiple technological devices (e.g., smartphones and tablets) (Dillman, Smyth, \& Christian, 2014). IB scholars began to use electronic surveys in the 2000s. Notwithstanding, most IB scholars continued not to (comprehensively) mention the steps used for administrating survey-based data collection, which jeopardized data collection equivalence. Moreover, issues relating to the translation of the questionnaire used to collect survey data were rare, despite IB scholars recognizing the importance of cross-cultural equivalence, and comparability of data and measures (Mullen, 1995; Singh, 1995).

Data collection equivalence introduces complexity distance due to three comparability challenges associated with cross-national survey-based data which relate to the sampling frame, data collection procedures, and samples themselves. Considering such challenges by survey-based scholars is important because not acknowledging them compromises the rigor of collected data and the validity of undertaken analysis (Chidlow, Ghauri, Yeniyurt, \& Cavusgil, 2015). Addressing such challenges meticulously is an arduous task because it requires a time-intensive, comprehensive approach from scholars. Such effort is important regardless of the widely accessible technical advances in the form of available online platforms for undertaking electronic survey data collection that not only aims at lowering survey administration costs but also helps to lower perceived behavior control.

Despite repeated scholarly attention centered on issues relating to the data collection equivalence (Green \& White, 1976; Hult et al., 2008) as well as evidence that supports adoption of credible survey-based data administration procedures (Chidlow et al., 2015; Harkness et al., 2010; Nielsen, Welch, et al., 2020), the comparability challenges prevent a reduction of the complexity distance that, in turn, 


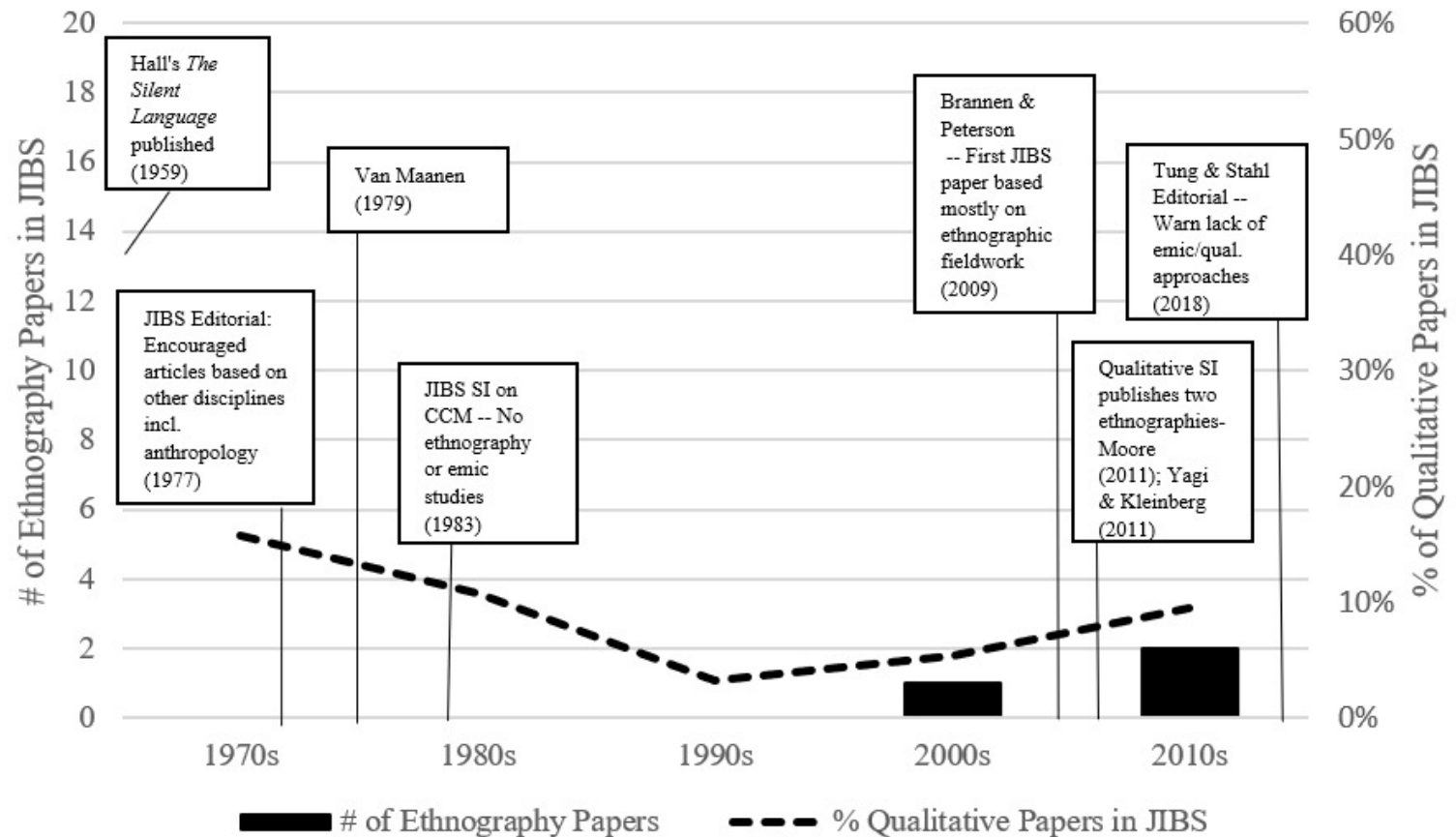

Figure 2: Delayed Low Adoption in IB Research: Ethnography1,2

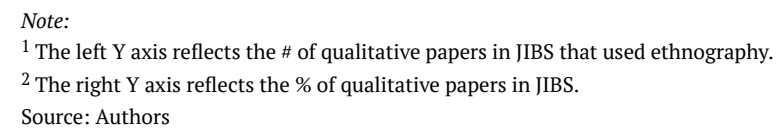

continues to adversely affect attitudes toward a change of a scholarly behavior. Because of that, it appears the low adoption of data equivalence by IB scholars puts the credibility of survey-based data into question.

\section{CONCLUSION}

This article sought to enrich our understanding of adoption of research methods innovations while focusing on translational distance and complexity distance for IB scholars. Examining JIBS articles over a 50-year period, we identified scholarly initiatives and technical advances that helped reduce translational distance and complexity distance for some research methods innovations (e.g., Heckman models). However, other innovations - notably data collection equivalence procedure and ethnography - have yet to shorten these distances and adoption remains largely elusive.

While progress has been made to reduce translational distance and complexity distance associated with some analytical techniques, concerns remain for others centered on data collection equivalence and ethnography. Our concern is that data collection needs to be in balance with analytical technique. Otherwise, IB scholars risk using increasingly advanced analytical techniques on less credible data, thus jeopardizing reliability of analyses and results. We acknowledge that some of the adoption issues may be journal spe- cific. Moreover, change may already be underway.

We recognize that our case studies reflect only one IB journal and, thus, we would like to encourage further analysis of methodological issues and trends across time and a wider scope of journals. While some methodologies may not (yet) be adopted in JIBS, they might be adopted in other IB journals. For example, the NKC methodology, which is a research method for simulating a firm as a complex adaptive system, seems to align with the ethnography case as nonadoption by JIBS, even though it has been adopted in the Journal of International Management in light of translational efforts by Levinthal (1997). ${ }^{2}$

Our study suggests that the IB community has made better progress to reduce translational distance and complexity distance for analytical techniques than for survey data collection and qualitative research. Moreover, our findings suggest that qualitative methods bring with them high time-based learning and opportunity costs that seem to present fewer issues with quantitative methods (especially studies that use purchased data sets), thus creating a growing distance gap. Reflecting on the growing complexity and translational distance gap, we note that doctoral academic training focuses on econometric techniques at the expense of data collection - especially for primary data.

We offer the following four-step action plan that, over time, can alleviate the above issues and close translational and complexity gaps in the IB community. 


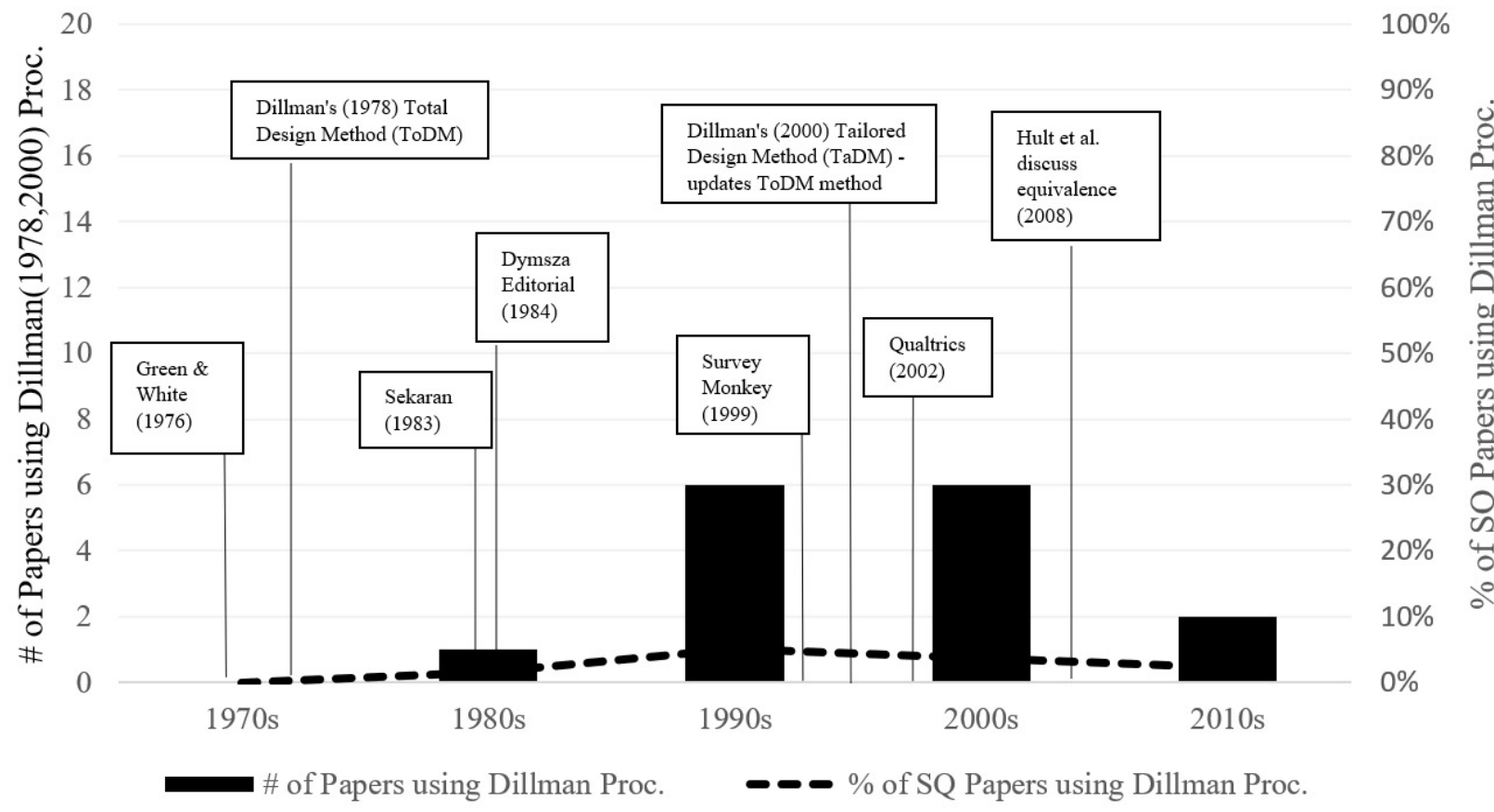

Figure 3: Low Adoption in IB Research: Data Collection Equivalence Procedures in Survey-Based Studies ${ }^{1,2}$

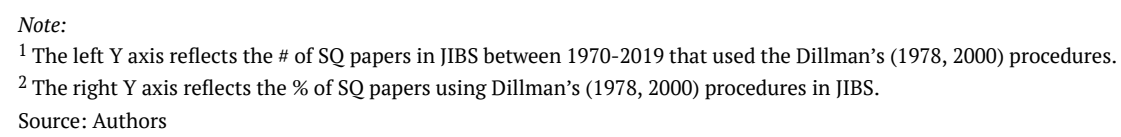

- Open access to a range of methodological resources available to authors and reviewers via their scholarly communities and journals.

- Continuous professional methodological development provided by scholarly communities and higher education institutions.

- Awareness of methodological diversity and best practices by engaging in with expertise external to the IB field.

- Compliance with data credibility, transparency and replicability principles.

As a scholarly community, we collectively need to make a more concerted effort, first, to expand the resources available to authors and reviewers, in line with the series of editorials in JIBS that explain expectations for reporting methods in scholarly outputs. Second, we need to educate ourselves about less-used qualitative methods and the subtleties of data collection in an IB setting. Methodological training activities can be a useful forum for such a continuous professional development. For example, the Academy of International Business Research Methods Shared Interest Group (AIB RM-SIG) in collaboration with the Consortium for the Advancement of Research Methods and Analysis (CARMA) has been offering a number of diverse workshops, clinics and masterclasses to all AIB's members, during the AIB's annual meetings, in order to provide learning opportunities on research methodologies. Third, we contend that the IB community can build methodological bridges to other fields by inviting external experts to participate in our scholarly forums for continuous professional development - which is common in many careers. Finally, due to the pressing need to improve the ways in which scientific outputs are evaluated by academic and funding agencies, academic associations and journals have a great opportunity to encourage sharing of research data, in order to ensure compliance not just with the code of ethics but also with research transparency in an actionable, sensitive and pragmatic way (Beugelsdijk, van Witteloostuijn, \& Meyer, 2020; Eden, 2010; Miguel et al., 2014). Given the greater focus on data transparency, the environment may be right for reviewers and editorial teams to be more proactive in requiring, for example, evidence of data collection equivalence and the context in which data was collected as part of the submission and review process.

We hope this AIB Insights article will serve as a first step in the direction we propose by illuminating the translational and complexity distances that "hamper" methodological adoption and innovation in IB research. After all, as a scholarly community, we should embrace the opportunities to contribute to and move forward ongoing research debates by using a wider range of methodological approaches and being open to alternatives.

\section{ACKNOWLEDGMENTS}

The authors would like to thank the Special Issue Editor William Newburry for handling our manuscript as well as two anonymous reviewers for their constructive feedback and guidance during the review process. 


\section{ABOUT THE AUTHORS}

Stewart Miller is Professor of Management at The University of Texas at San Antonio (USA). His research interests lie in the areas of the liability of foreignness, internationalization, CSR and research methods. He is the President and one of the co-founding members of the Academy of International Business Research Methods-Shared Interest Group (AIB RM-SIG). He was the 2020 Chapter Chair for the AIBSoutheast U.S. Chapter Annual Conference (virtual). He is a member of the editorial review boards for the Journal of Management Studies, Journal of International Business Studies, Management International Review and Global Strategy Journal.

Catherine Welch is an Associate Professor in International Business at the University of Sydney, (Australia) and Distinguished Visiting Professor at Aalto University. Her research interests lie in the areas of qualitative research methodology and process approaches to studying firm internationalization. She is one of the co-founding members of the AIB RM-SIG.

Agnieszka (Aggie) Chidlow is Professor of International Business at the University of Birmingham (UK). Her research interests lie in the areas of location choices of MNEs as well as methodological issues in international business with a specific focus on survey data. She is one of the cofounding members of the AIB RM-SIG and before becoming the AIB RM-SIG Vice-President for Responsible Research Methods in 2020 she was the AIB RM-SIG Vice-President Program between 2016-2020. She is also currently a Working Board Member of the Responsible Research in Business and Management Network (RRBM) and Senior Editor for International Business Review.

Bo Nielsen is Professor of Business Strategy at University of Sydney (Australia) and Adjunct Professor at Copenhagen Business School. His research is at the intersection of strategy, international business and economic geography. He is one of the co-founding members of the AIB RM-SIG and serves as Consulting Editor in JIBS. He has published more than 50 articles in peer-reviewed journals. His recent coedited book "Research Methods in International Business" is available at Palgrave Macmillan.

Diletta Pegoraro is in her final year of her $\mathrm{PhD}$ at Birmingham Business School, University of Birmingham(UK). She holds a position as research assistant at the Department of Economics and Management, University of Trento. Her main research interests are in the field of international business, GVCs, and economic geography. She is an Officer at the AIB RM-SIG.

Maria Karafyllia is Assistant Professor of Strategy at Nottingham University Business School, University of Nottingham, UK. Her research interests include paradoxes of strategy and innovation, unlearning, domestic market effects on internationalization, open innovation, necessity entrepreneurship, and market ambidexterity.

Submitted: December 01, 2020 EDT, Accepted: March 27, 2021 EDT 


\section{REFERENCES}

Beugelsdijk, S., van Witteloostuijn, A., \& Meyer, K. 2020. A new approach to data access and research transparency (DART). Journal of International Business Studies, 51: 887-905.

Boussebaa, M., Sinha, S., \& Gabriel, Y. 2014. Englishization in offshore call centers: A postcolonial perspective. Journal of International Business Studies, 45: 1152-1169.

Brislin, R. 1970. Back-translation for cross-cultural research. Journal of Cross-Cultural Psychology, 1: 185-216.

Cantwell, J., \& Brannen, M. Y. 2011. Positioning JIBS as an interdisciplinary journal. Journal of International Business Studies, 42: 1-9.

Chidlow, A., Ghauri, P., Yeniyurt, S., \& Cavusgil, S. T. 2015. Establishing rigor in mail-survey procedures in international business research. Journal of World Business, 50: 26-35.

Dillman, D. 1978. Mail and telephone surveys: The total design method. New York: Wiley \& Sons.

Dillman, D. 2000. Mail and internet surveys. The tailored design method (2nd ed.). New York: Wiley \& Sons.

Dillman, D., Smyth, J., \& Christian, L. 2014. Internet, phone, mail, and mixed mode surveys: The tailored design method (4th ed.). John Wiley \& Sons.

Dymsza, W., \& Vambery, R. 1977. From the editors. Journal of International Business Studies, 8: 4.

Eden, L. 2010. Letter from the editor in chief: Scientists behaving badly. Journal of International Business Studies, 41: 561-566.

Eden, L., \& Nielsen, B. B. 2020. Research methods in international business: The challenge of complexity. Journal of International Business Studies, 51: 1609-1620.

Green, R., \& White, P. 1976. Methodological considerations in cross-national consumer research. Journal of International Business Studies, 7: 81-87.

Hall, E. 1959. The silent language. New York: Doubleday.
Harkness, J., Braun, M., Edwards, B., Johnson, T., Lyberg, L., et al. 2010. Survey methods in multinational, multiregional and multicultural contexts. Hoboken, N.J.: Wiley.

Heckman, J. 1979. Sample selection bias as a specification error. Econometrica, 47: 153-161.

Hult, G. T. M., Ketchen, D. J. J., Griffith, D. A., Finnegan, C. A., Gonzalez-Padron, T., et al. 2008. Data equivalence in cross-cultural international business research: Assessment and guidelines. Journal of International Business Studies, 39(6): 1027-1044.

Lenartowicz, T., \& Roth, K. 1999. A framework for culture assessment. Journal of International Business Studies, 30: 781-798.

Levinthal, D. 1997. Adaptation on rugged landscapes. Management Science, 43: 934-950.

Miguel, E., Camerer, C., Casey, K., Cohen, J., Esterling, K. M., et al. 2014. Promoting transparency in social science research. Science, 343(6166): 30-31.

Mullen, M. 1995. Diagnosing measurement equivalence in cross-national research. Journal of International Business Studies, 26: 573-596.

Nielsen, B. B., Eden, L., \& Verbeke, A. 2020. Research methods in international business: Challenges and advances. Research methods in international business: 3-41. Cham: Palgrave Macmillan.

Nielsen, B. B., Welch, C., Chidlow, A., Miller, S. R., Aguzzoli, R., et al. 2020. 50 years of methodological trends in JIBS: Why future IB research needs more triangulation. Journal of International Business Studies, 51: 1478-1499.

Rouleau, L., De Rond, M., \& Musca, G. 2014. From the ethnographic turn to new forms of organizational ethnography. Journal of Organizational Ethnography, 3: 2-9.

Sekaran, U. 1983. Methodological and theoretical issues and advancements in cross-national research. Journal of International Business Studies, 2: 61-74.

Shapiro, J., Ozanne, J., \& Saatcioglu, B. 2008. An interpretive examination of the development of cultural sensitivity in international business. Journal of International Business Studies, 39: 71-87. 
Shaver, J. M. 1998. Accounting for endogeneity when assessing strategy performance: Does entry mode choice affect FDI survival? Management Science, 44(4): 571-585.

Singh, J. 1995. Measurement issues in cross-national research. Journal of International Business Studies, 14: 61-73.

Theil, H. 1953. Repeated least squares applied to complete equation systems. The Hague: Central Planning Bureau.
Tung, R. L., \& Stahl, G. K. 2018. The tortuous evolution of the role of culture in IB research: What we know, what we don't know, and where we are headed. Journal of International Business Studies, 49: 1167-1189.

Van Maanen, J. 1979. Qualitative methodology. Administrative Science Quarterly, 24: 519-671.

Westney, D. E., \& Van Maanen, J. 2011. The casual ethnography of the executive suite. Journal of International Business Studies, 42: 602-607.

Wright, P. 1928. The tariff on animal and vegetable oils. New York: MacMillan. 